\title{
AN UNSUITABLE JOB FOR A HUMAN
}

\author{
Career opportunities.
}

\section{BY MICHAEL HAYNES}

"A bsolutely out of the question!" Commander Zonj said, smacking his claw on the desk for emphasis.

Captain Glanx always felt uneasy when he had to visit the Commander's office at Central Base and suffer the stare of Zonj's compound eyes. Today, in particular, after the way things had gone on his first mission as Captain, it would have been easy to bow his head and skitter off without another word. But he felt responsible for how things had turned out. And, beyond that, he truly wanted to help the human waiting outside.

"Sir, I realize there isn't much precedent for what I'm proposing..."

"There isn't any precedent for it! Bad enough that you let two aliens on board your ship. Aliens, I might add, that you were so ill-equipped to care for that one of them has since died. But now you show up in my office and suggest that we employ the survivor? And as a ship's pilot, no less?" Zonj waved his four arms in consternation. "This is not an auspicious start to your captaincy, Glanx!"

It should have been an easy mission, a routine survey trip to a system with a single, planet-bound sentient race. But as soon as the initial data were analysed, the cultural scientists were amazed by the advances made by the people who called their world Earth. Not only had they advanced beyond using super-light gases as their sole means of flight, but they had evidence of rocket programmes that could soon bring their civilization into space.

The scientists pushed to stay longer and longer, especially once they had determined that there was political unrest in one of the most technologically advanced sectors of the planet. But the ship's cloaking system was behaving erratically and Glanx had declared the mission complete. The crew readied for the journey home while the ship idled over a large expanse of water.

"Captain," said one of the bridge crew, "we're having trouble with the cloak again. Some signals from below are disrupting it."

Glanx recalled the primary rule of surveying - "Don't be seen" - and promptly ordered her to increase the cloak's power. Afterwards, he learned that this decision had fatally crippled the ability of the humans to communicate with their peers.

A while later, the same crew member alerted Glanx to the crash of a human flying vessel nearby. She also pointed out that humans were ill-suited to survival in water.

There was a sudden buzz by Glanx's head.

"Captain, think of the opportunity we conscious, clinging to the wreckage. One, much more seriously injured, had indeed died not long after being brought on board.

Communication with the other human had been difficult at first. The translation systems were designed to render Council Standard from Earth languages, not the reverse. This limitation was eventually overthe survivor could proWTSE CIN

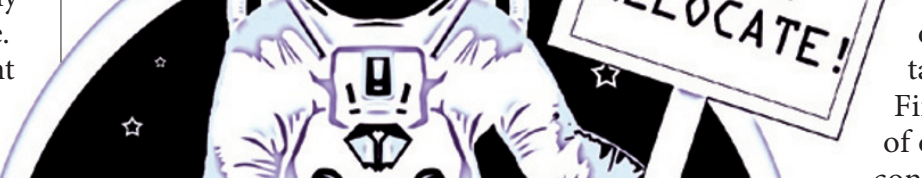
only one who wanted to talk to the human after that. First, he did so from a sense of obligation. But from their conversations, he found that they shared a desire to explore and that this human was a particularly accomplished practitioner of their flight technologies. Soon, he viewed their conversations as a highlight of his day.

And so he stood before Zonj,

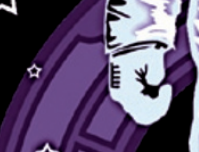
. .

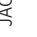

